\title{
Consideration of Culture in the Development of Homeeconomics Curriculum in Nigeria
}

\author{
Ozioma C. Azubuike \\ Department of Home Economics, \\ Federal College of Education (Technical), \\ Umunze-Anambra State, Nigeria \\ Uloma Charity Oguzor \\ Department of Home Economics \\ Federal College of Education (Technical), \\ Omoku-Rivers State, Nigeria
}

\section{Doi:10.5901/jesr.2013.v3n9p183}

\begin{abstract}
This paper tries to examine the consideration of culture in the development of HomeEconomics curriculum in Nigeria. The cultural element which the school draws from include the society's values, norms, religion, belief, languages, customs e.t.c and other attributes which are transmitted and local acquired. The role of culture in school should be appreciated particularly in HomeEconomics curriculum development which is practically oriented subject that deals with people's clothing, feeding, housekeeping, e.t.c. This will be a guide towards helping the teachers of the subject know how to deal students with culural diversity.
\end{abstract}

\section{Introduction}

The concept of culture and curriculum have come with various meaning and definitions by different authors. A synthesis of all these meaning will put them as embracing all the activities experiencedd by an individual learner under the supervision of the school. Homeeconomics curriculum thus refers to the group of courses or planned experiences in the proper sequence designed to prpare an individual for curriculum should neglect the following features:

- Aims, goals, and objectives emanating from the needs of the people.

- Subject matter content

- Learning activities

- Evaluation

Since the above is the aim of curriculum and culture is about the way of life people therefore, culture should be considered for curriculm development to be success and a effective implementation.curriculum has been viewed as the analysis and study of how schools are created, organized and made to function. The concept and the field of the curriculum therefore should not be limited to the purposes, content and method in educational process. Rather, it should be extended to examine those critical factors in the social-cultural, socia-politicals, social economic, and social ecological environment in which schooling takes place. Consequently, and by it's nature, what constitutes the curriculum $s$ a selection from the culture of the society is a critical reflection on the peculiarities of the most stable values of the society, the dynamics of members of the society and portions of the society's cultural heritage that deserves to be propagated.

Culture-curriculum is better understood when conceptualized in a socio-culture contex. in this way, one attempts to analyze and evaluate the schooling process against the influence of the 
numerous forces or factors in the social envronment bearing in wind that the knowledge which the school transmits derives from sort of ideologists values, philosophies, beliefs and norms all of which are perculiar to various sociao-cultural groups. besides their inabbility, culture therefore, is the nucleus of curriculum in any society.

The cultural elemnts which the school draws from include the society's values, Norms religion, beliefs, taboos, tradition, language, music, customs,occupations, skills arts, aesthetics and other attributes which are society trasmitted and locally acquired including modes of problem solving. To this extend, there is nothing that the school teaches that does not have a base in that society.

While appreciating the role of culture as the source of school knowlege, it is imprtanr to recognize the fact that these cultural elements are not the same in all cultures neither are they static within culture.

Culture differences among societies may account for some observed differencies in Educational policies and practices in these systems. Since the curriculum cannot exit outside the socio-cultural environment, the curriculum planner/worker should be fully guided by a good knowledge of the culture of the society for whom the curriculum is intended.

According to Urevbu, efforts will be largely wasted unless what we teach are relevant to the values of our culture and the resource at our disposal.

Drawing upon some of the theoritical wright from Dennis Lawton's concept of common culture curriculum,some of the problems of planning a Nigeria school curriculum, such as Nigeria school curriculum, such as Nigeria inability to evolve a philosophy of Education of her own, how to use education to preserve our diverse societal values: hoe to make judicious selection from the traditional Nigeria culture and from Anglo american values and resolving the conflict from the different between them,determine the extend to which psychological theories of learning are applicable to Nigeria children, and how to organise the curriculum in stages and sequencies in orther to achieve maximum psychological validity create a significant gap between the school curriculum and reality.

Society as the basis of educational process. It is the value system of the society that undelies the formulation of education purposes. Besides, the various aspects of the culture constitute discrete field of knowledge. Culture therefore produces the needed content for the curriculum. It select the desirable and worth while aspect of the culture for propagation.Thus, the curriculum represent a continous insight into the life of the society by the school with a view to bring about improvement. The emphasis on aspects of the culture suggest that everything about the culture cannot for in the school knowledge. It requires a selection Lawton developmed a model to elaborate on how curriculum planner could go about selecting from the culture of society. The model consists of five stages as illustrated below:

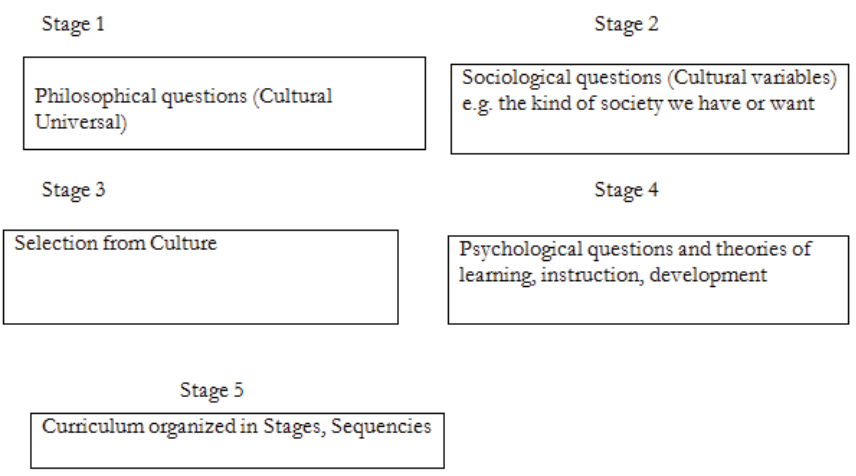

Thereafter, the educational implications of such experience are explicates and defined as educational purposes. Cultural universal is likely to create serious problems in a societies such as 
Nigeria. An example could be drawn from the national language policy in Nigeria, which requires secondary schools to teach some of the pratically oriented subjects such as home economics in the mother tongue of the students for example housa, igbo, and yoruba. Though the national policy on education provides a pleasure justification for this in terms of promoting cultural heritage and national unity, critics are afraid of the political dangers of using the curriculum to legitimaate the recognition, dominance of supremacy of three languages. Selection from the culture of the society as in stage three, is not an easy task even after all the philosophical and sociological question. If education is seen to preserve, transmit and reflect the cultural heritage of a society, then curiculum may be regarded as a structural series of learning experiences extended to individuals through education curiculum design, therefore, consider as a first and basic components needs of the society. It is worthwhile to study society and see its problems, values and needs at any particular time. The students interest, needs and level of development should be considered by the designer. Societal needs are subject to change; thus are different times society will have different needs. For example,technological improvements have affected home life in such a way that society now needs instruction in the science of homeconomics. Therfore, a curriculul in homeeconomics should increase the basic principles of physic,chemistry and biology.

The objectives of education can be at either national or state level, they may include transmission of culture, establishing national unity, development of the potential of the individual, economic efficiency and self fulfilment.

The objective of homeeconomic education may also fall within this definition. Specifically, objective may describe the standard to be attained to every student following a particular course. Some of the objectives develop for food and nutrition in a syllabus prepared at a homeeconomics workshop held at Ibadan in 1972 can better illustrare Bloom's classification of curriculum objectives. The following are some of the objectives:

1. To appreciate the importance of health

2. To teach the priciples of cookery in relation to conserving the nutritive content of foods and to apply those principles to preparation of food locally available foodstuffs.

3. To develop the ability to select a balanced diet from available foods.

The first is from the effective field, the second cognitive psychomotor and the third cognitive capability.

The implication of analysis for the planners of homeeconomics programmmes, therefore, is that the acquisition of fact,theories and principles and technical skills is needed for success on the practical side of the course. If this dictum is stricly followed, It will greatly help the planners to structure a suitable curriculum to give the students a balance education.

Curriculum development serves aas an input component for curriculum therefore, is a structural series of intended learning outcome. Curriculum prescribeds the results of instruction. It does not prescribe the means i.e the activities, materials and even the instructional content to be use in achieving the results. Curriculum indicates what is to be learned, not why or how it should be learned.

When developing the curriculum, the homeeconomics teacher must use her knowledge of the basic principles of curriculum desgin. She must use the relevant curriculum approaches and procedures. Each pattern of curriculum organisation adopts a certain idea or scope because it follows certain special criteria for sequence, continuity and integration. Each partern therefore provides for these characteristics in a different manner, although they are related.

Some of the approaches to curriculum in HomeEconomics are: The subject matter approach, integrated curriculum, job analysis approach, the occupational analysis approach competency approach, the modular approach e.t.c.

The subject matters apprroach constitutes a logical and effective method of organizing new knowledge and therefore an effective method of learning it. By following organized bodies of subject matter, a student can build his store of knowledge more effectively and economically.

Integrated curriculum is a modification of subject curriculum and canbe used effectively in 
homeEconomics. It provide flexibility in meeting students' need and interest and permits a graduation and distribution of course material in keeping with successive levelof comprehension as such student gain maturity and understanding.

Job analysis approach includes a number of task. This approach is one of the most often used to provide pre and in-service professional trainig to occupational teachers. It's places emphasises on the knowledge, skills, attitude and judgements that are generally required for the successful performance of a task rather than all the components comprising the task.

The modular approach is the unit or standard of measurement. It is the unit of standard of curriculum based on the development of entry level competencies of the students. In the modular desgin the students and their occupational goals from the basis for programme planning. With the modular approach, the total homeeconomics programme divided into unit refered to as modules. These modules will each take approximately thirty hours of instructional time to achieve with the average group of students. The homeeconoomics desgin has the occupational clusters while developing the curriculum.

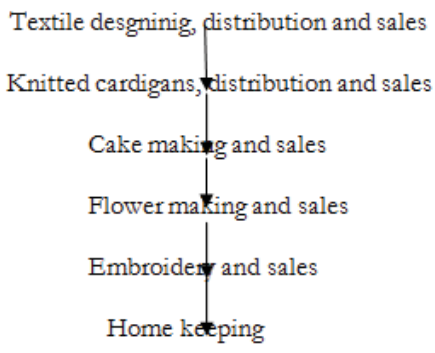

Every student irrespective of the culture will be able to develop at least to minimun entry level in one homeeconomics occupation.

In connclusion, curriculum is not a system but the output of one system and input into another; curriculum is a guide to instructional systems which begin with planning.

The mainn aim of homeeconomics programmes is to prepare students to become teachers and professionals in homeeconomics. The central concern of homeeconomics teacher education should be the development of persons who find fulfillment in their commitment to the teaching of the subject

The need to train professional, competent homeeconomics teachers has led to the introduction of homeeconoics education at three levels of three levels of the school system. These include higher elementary (or grade II) Teacher trainig colleges, Advanced teacher trainig colleges usually referred to as college of education. Undergraduate studies in the universities.

Higher Elementary Level: At this level, the trainig is geard towards prparing teachers for primary schools. Student who are admitted into this programme need the minimum qualification of a first school leaving certificate. Their duration of study depends on the entry level qualification of the students. Those with the primary six or moder school leaving certificate spend a minimum of four(4) years, while those who have passed west African school certificate examination take one year to become qualified.

The programme at this level made up of both general and professional education. Students at the end of their course offer subject as geography, history, mathematics and homeeconomics. Thus the programme prepares a student for teaching all subjects in the primary school curriculum. Those who teach homeeconomics after completing their course are perhaps the one who distinguished themselves in the subject while at school especially intrested in it.

College of Education Level: The at studies at this level is geard towards giving professional trainig to a student in one or two particular subjects, which will enable her to teach in secondary schools. Some of the graduates may also teach in the grade II teacher training institutios. 
Students admitted in the department of homeeconomics in these institutions take some courses related to homeeconomicsand education alone, and at this stage the training is fairly specialised. The student also experience teaching practice for a minimum period of three months. They must possess a minimum qualification of either West African School Cerfificate with at least four credit in related subjects, especially biology, and chemistry, or needlework and cooking or teacher's Gradell certificate with either credit or merit in homeeconomics- related subjects and English or General Certificate of Education (G.C.E) at ordinary level. Both categories of students are expected to spend a minimum of three years training.

Under Graduate Level: The programme at this level is geared toward preparing technical skilled and professionally competent teachers of homeeconomics who will be expected to teach at the colleges of education. Grade II teacher's college or secondary schools.

As mentioned before, homeeconomics education has so far been introduced into two of our universities; The university of Nigeria, Nsukka, University of Benin and Ahmadu Bello University Zaria.

These universitties offer a four-year or three-year programme, at the end of which Bachelor of science degree is awarded.

These are the three levels at which homeeconomics teachers are trained at present.

The private sectorsare not left behind in following curriculum of homeeconomics programme, Furthemore, in order to gain a true knowlege of the standard of homeeconomics education on primary schools, an attemt will made to analyze:

i. The curriculum for primarys school homeeconomics

ii. The selection of teacher for homeeconomics in the primary school and

iii. The programme of training for the homeeconomics teacher in the secondary schools.

From the curriculum of homeeconomics in Edo State of Nigeria, the theme of the curriculum is seen as the child in the home; in developing this theme to realize the above aims and objectives, six areas of homeeconomics have been identified as sub-theme or units for the curriculum. Each area is expected to be taught at particular stage of primary education. These sub-theme include;
A. - Clothing and textile
B. - Home and family living
C. - Food and Nutrition
D. - Good grooming
E. - Home and family living
F. -Family and human relation

Unit A deals with all six classes while units $B, C$ and $D$ start only in primary three, and units $E$ and $F$ in primaries five and six. This arrangement is in recognition of the varying shapes of the child's maturity to ensure that more difficult concepts are introduced at the appropriet stage of development.

The planner advice that the teacher concerned with the use of the syllabus should be originally and resourceful in her lesson planning the contents of the curriculum tend to tally with the set objectives for the classes and are within the chronolgical age and expected performance of the students/pupils.

\section{Culture and Curriculum Development in Homeeconomics}

In many communities today our general society is reflected in the cultural diversity of our classrooms. Whe we refer to students as beeing cultural different we are thinking of those whose racial, nationality, religious, and ethnic characteristic distimguish them from the majority. Their speach, manners, attitudes and habits may be distinctive. They may have backgrounds and personality structure that differ significantly from others.

Culture diversity may present a variety of problems to a teacher. The students are exposed to 
two sets of norms, one set at home and another set as school. Often, these norms pull opposite direction. Other students respond to their peculiar behaviour with prejudice. Teachers and students may be inclined to treat all members of a particular minority groups, all too often the teacher fails to recognize special problems and poteentialities of an individual.

The culture different helps to become acquainted with the community, the homes and families of students, and the individual students themselves. As you become acquinted, you will be able to identify which minority groups are present and to what extent.

A large group deserving of an attention is compained of culturally disadvantages families some culturally different families may be culturally disadvantaged, but these terms are by no means synonymous.

The major problems confronting diadvantaged families include; housing, shortage of adequate housing for low income families, opposition of community associations and individuals to having culturally.

\section{Conclusion}

The culture of any society affects its curriculum. Hence, culture includes everthing that can be communicated from one generation to it's successor. This involves a whole ways of life, a structure of feeling and peoples heritage which is made up of both material and non material aspects of life since that word curriculum has come to be used reference to education, and is now taken as a councel which students undertakes as they compete for high grades, passses, certificates or other forms of academics rewards, in addition, there can be no education without culture because education is a process that led continuity and meaning to lives. Hence, issue curriculum comes to be used in relation to education, The only general view about it is that it is a programme of studies to be completed by teachers and learners which need to be developed through the influences of the society's culture.

\section{Recomendation}

Conception and perception of culture in the development of homeeconmics programme should be considered and upgraded.

Enough awarnesss should be created to the curriculum planners in the development of homeeconomics programme.

The society sholud be encourage to ask psychological and sociological questionns that will imbibe culture in the curriculum of homeeconomics programme.

The government should also know that culture of differnt ethnic groups will enhance the teaching/ learning processes of homeeconomics programme, therfore she should allow culture to be paramount in the curriculum planning of homeeconomics progrmme.

\section{References}

Federal Government Syllabus for Grade II Teacher Training, Curriculum for Home Economics (Lagos, Nigeria, 1974), Pg. 214.

Iyamu, E.O (2005) culture in the development of curriculum. Pg. 84: 2005

Olaitan, S.O (2001) Introduction to the teaching of Home economics Pg. 59

Okobiah, O.S (1984) "The New National Policy on Education and the Development of social studies curriculum for Nigeria schools" Nigerian J ournal of curriculum studies Vol. III,No. 11984.

Onwuka, U, (ed) Curriclum Development of Africa. Onitsha: African-Feb

Pratt, David (1980) Curriculum Design and Development New York. Harcourt Brace J ov. Inc. 1980 
